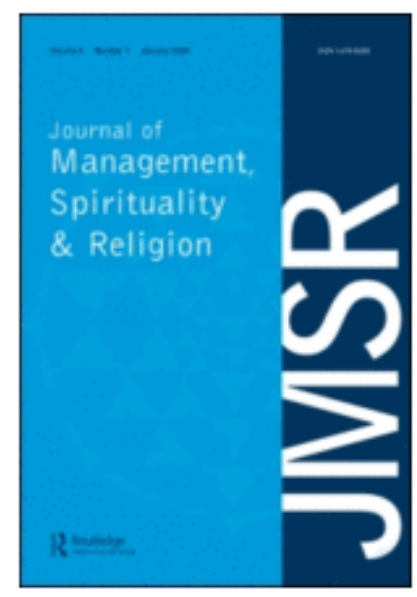

\title{
Spiritual leadership development: An exemplar protocol
}

\begin{tabular}{|r|l|}
\hline Journal: & Journal of Management, Spirituality \& Religion \\
\hline Manuscript ID & RMSR-2019-0077.R1 \\
\hline Manuscript Type: & Special Issue Article \\
\hline Keywords: & $\begin{array}{l}\text { Spirituality, Leadership, Leadership development, Contemplative } \\
\text { practice, Organizational development }\end{array}$ \\
\hline Keywords: & leadership, spirituality, organizational development \\
\hline \multicolumn{2}{|l}{} \\
\hline
\end{tabular}

\section{SCHOLARONE Manuscripts}




\title{
Spiritual leadership development: An exemplar protocol
}

\author{
Abstract \\ The nexus of spirituality and leadership infuses many leadership theories. \\ However, there is a gap in our understanding regarding how organizations integrate \\ spirituality with leadership development. This article makes a significant contribution to \\ understanding the intersection of spirituality and leadership development by examining a \\ specific facilitation protocol. It is a natural bookend to the seminal article titled \\ "Spirituality for Business Leadership: Reporting on a pilot course for MBA's and CEO's" \\ (Delbecq, 2000) in which André shared his first attempt at such work. In contrast, the \\ protocol discussed in this article has been refined by André's continued leadership and \\ practice in this area. As well, this protocol was designed and implemented as a formal \\ leadership development initiative within an organization. In this paper, we begin with a \\ literature review on spiritual leadership development: the intersection of spirituality, \\ leadership and learning; the primacy of contemplative practice; and the importance of \\ structure. Second, we describe a leadership development program design that explicitly \\ integrates spirituality. Finally, we discuss the implications of this protocol for future \\ practice and research on spiritual leadership development.
}

Keywords: Spirituality, leadership, leadership development, contemplative practice, organizational development 


\section{Introduction}

Scholars and practitioners increasingly recognize that effective governance begins with the interiority of the individuals charged with this task (Scharmer and Kaufer 2013; Mackey and Sisoda 2014). Interiority includes one's spirituality, defined as "the capacity of the human consciousness to apprehend ultimate meaning and ultimate value" (Tackey and Harris, 2015 as cited in Tackney et al. 2017, p. 246). However, the dominance of scientific materialism and "[o]bjectivity-seeking management education" (Schmidt-Wilk, Heaton, and Steingard 2011, p. 252) has resulted in a gap in our understanding regarding how organizations integrate spirituality with leadership development. The majority of scholarship draws on university students in management classrooms (see Delbecq 2000; Pavlovich 2010; Waddock and Lozano 2013; Marcic 200; Bento 2000). Scholarship in organizational settings largely consists of anecdotal references to elements of spirituality in leadership development initiatives and corporate visions (see Cavanagh 1999; Howard 2002) and, at the other extreme, evidence of impact from teaching a particular contemplative practice (e.g. Schmidt-Wilk, Alexander, and Swanson 1996; Schmidt-Wilk 2000; Charles, Travis, and Smith 2014). This article makes a significant contribution to understanding the intersection of spirituality and leadership development by examining a specific facilitation protocol utilized with a senior leadership team.

This article is a natural bookend to the seminal article titled "Spirituality for Business Leadership: Reporting on a pilot course for MBA's and CEO's" (Delbecq, 

explored in this article reflects a process André refined and delivered in the final years of his practice. As well, this protocol was designed and implemented as a formal leadership development initiative for a group of senior executives in an organization. André and Bill McCready, Senior Fellows from the Ministry Leadership Center, conducted interviews with participants following the pilot implementation of this protocol. They subsequently invited Stacie Chappell to the research team with the intention of sharing the protocol with a broader academic audience. The result is this article. The initial manuscript was presented, with André present, at the 2016 Academy of Management. It seems fitting to include an examination of this protocol in this special issue honoring André's life's work. The article begins with an exploration of spiritual leadership development through: 1) the intersection of spirituality, leadership and learning, 2) the primacy of contemplative practice, and 3) the importance of structure. Next, we describe a leadership development program design that explicitly integrates spirituality: the Senior Leadership Forum (SLF). Finally, we discuss the implications of the SLF protocol for future practice and research on spiritual leadership development.

\section{Intersection of spirituality, leadership and learning}

At the end of the last Century leadership development took an ontological turn, moving away from knowledge acquisition and objective analysis and towards relationship, reflexivity, and the inner journey (see Bolman and Deal 2001; Palmer 1999; 
Kouzes and Posner, 2006). For example, Vail $(1996,126)$ asserted that "leadership is learning" and explicitly connected the being dimension, learning about oneself, to leadership. Antonacopoulou and Bento $(2004,82)$ describe this with a trapeze metaphor:

This ability to learn, however, requires a leader who is willing to feel the vulnerability implicit in not knowing, an openness to experience that approaches each new situation as a circus artist who flies from one trapeze to the next, rather than clinging to the comforting security of the platform ... the kind of leadership where one is perpetually a reflective beginner and 'incompetence' is just the exhilarating flight between competently holding the trapeze of the past and tentatively grasping for the trapeze of the future.

The nexus of spirituality and leadership is important because the inside creates the outside. Spirituality is ultimately the meta-story of an individual's ontological assumptions. Qualities related to the spiritual journey are increasingly relevant to leadership: vulnerability, not-knowing, being a reflective beginner. In order to sit in not knowing, leaders must develop the capacity to presence, to let go and let come (Scharmer and Kaufer 2013). Developing one's spirituality requires exploring a series of nested relationships: with oneself, with others, with the natural environment and with a higher power (Howard 2002). As articulated by Howard (2002, 236), “[r]eal learning, and real spirituality, get to the heart of what it means to be human." Spiritual leadership development can build the capacity:

...to approach situations with an attitude of discernment rather than one of intervention; acceptance rather than control; letting go rather than holding on; with an attitude of listening rather than doing and in humility rather than in competence (Korac-Kakabadse, Kouzmin, and Kakabadse 2002, 180).

However, this will require learning experiences that move beyond the intellectual domain to acknowledge and engage the whole person (Tisdell and Tolliver 2001; Cowan 2005). 
Spiritual leadership development necessarily will include contemplative practice to develop the capacities for both individual mindfulness (Kabat-Zinn 2003; Hart 2004) and collective presencing (Scharmer and Kaufer 2013).

\section{Contemplative practice}

The spectrum of contemplative practices includes meditation, visualization, creative, relational, movement and ritualistic activities, as depicted in Figure 1, the Tree of Contemplative Practices (CMind n.d.). These practices are found in all major faith traditions. A growing body of evidence suggests the positive impact of contemplative practice on physical well-being, cognitive clarity and behavioral complexity (see McClintock, Rodriguez, and Zerubavel 2019; Sable 2014; Schmidt-Wilk 2000; SchmidtWilk, Alexander, and Swanson 1996; Slemp, Jach, Chia, Loton, and Kern 2019, etc.). Meditation can increase attention and emotional regulation, enhance neural plasticity, modulate brain activity, optimize immune and inflammatory systems, improve psychosocial functioning, and positively modify gene expression (Sivilli and Pace 2014; Reibel, Greeson, Brainard, and Rosenzweig 2001).

\section{Insert Figure 1 About Here}

Biberman et al. $(1999,5)$ were among the first to articulate the need for "deep process oriented learning" and explain in broad terms how rituals, guided reflections, music and other reflective activities might be used. The intention is to transcend the 
rational-empirical approach to teaching leadership (Lips-Wierma 2004; Kernochan, McCormick, and White 2007; Pavlovich 2010; Waddock and Lozano 2013). While there is no prescription around the what or how, it is commonly understood that "[t]he source of spiritual leadership is an inner-life practice" (Fry and Nisiewicz 2013, 5). Three practices prevalent in the literature on developing consciousness include reflection, mindfulness, and presencing (Pavlovich 2010). Reflecting involves rethinking, in order to relearn from the past and "contributes to loosening mental rigidity" (Pavlovich 2010, 195).

Mindfulness is intentionally paying attention to present-moment experience in a particular way, which enables greater clarity and awareness (Kabat-Zinn 2003; Pavlovich 2010). Finally, presencing is a combination of being mindfully present and bringing one's highest future potential into the moment (Scharmer and Kaufer 2013).

Contemplative practice develops the brain in a way that decreases innate reactivity and increases capacity to respond from a more complex perspective and/or understanding (Barney et al. 2015). Contemplative practice produces deep concentration and equanimity, establishing a base of calm from which to explore meaning, purpose and current challenges. Consequently, such practices are critical to transformative learning, which can only occur when frames of reference, points of view, and habits of mind are explored "to construe a new or revised interpretation of the meaning of one's experience" (Mezirow 1996, 162). They underpin the development of the spiritual leadership capacity 
for discernment, "a deep, broad and subjective approach in which one seeks access to fundamental wisdom when faced with complex choices" (Delbecq et al. 2004, 147).

\section{Appropriate levels of structure}

A particular challenge of transcending the rational-empirical tradition of leadership development to include more contemplative practices in leadership development, is the fear of getting lost in an amorphous quagmire. However, incorporating alternate instructional methods and shifting the focus from doing to being does not imply that spiritual leadership development initiatives should be unstructured. In fact, structure provides the necessary guide rails to ensure safety for participants.

Structure begins with intentional clarity for the learning intervention; clearly articulated learning objectives are critical for both facilitators and participants. Structure continues through the use of meaningful rituals that "provide a sense of security and common identity and assign meaning" (Deal and Kennedy 2000, 67). Unconscious mental models of traditional learning environments, with an emphasis on the cognitive domain, need to be explicitly renegotiated by introducing new group norms: how sessions begin, the types of interactions that are appropriate, and signals for shifting from one activity to another. A related structure is stable group membership. It is important that new members are not introduced once the group process gets underway as structured learning cohorts encourage a deeper level of reflection and critical questioning (Carter 2002; Ziegler, Paulus, and Woodside 2006; Wahid and Mustamil 2014). Other design elements that 
contribute to transformative learning include the presence of non-evaluative feedback and nonhierarchical status, voluntary participation and partner selection, shared goals and authenticity (Eisen 2001).

These structural supports create a container to invite and hold the religious plurality (Hicks 2003) necessary in contexts that link our spiritual and organizational lives. Rather than safely compartmentalizing these aspects, careful attention to structure can invite the sacred, defined by individuals in multiple ways, without relying on a single tradition or perspective.

\section{The Senior Leadership Forum: An exemplary case study}

The Senior Leadership Forum (SLF) ${ }^{1}$ is an exemplar of the intersection of spirituality, leadership and learning. The SLF protocol explored in detail in this paper is the pilot program delivered to the Oregon Senior Leadership Team of Providence Health and Services. Providence Health and Services in Oregon is a part of the greater Providence Health and Services operating across Alaska, Washington, Oregon, Montana and California. It is a not-for-profit network of hospitals, health plans, physicians, clinics, home health services and affiliated health services. All ten members of the Oregon Senior Leadership Team accepted the invitation and attended the full program. The cohort for

\footnotetext{
${ }^{1}$ Administered through the Ministry Leadership Center, see www.ministryleadership.net 8
} 
SLF pilot represented the most senior leadership level in the Oregon division of the organization: Regional Chief Executive, Chief Public Affairs and Marking Officer, Chief Executive (Delivery), Chief HR Officer, Chief Mission Integration Officer, Chief Operating Officer, Chief Executive for Diversity, Chief Strategy Officer, Region Director of Project Management. The group was predominantly male (eight of ten participants).

The learning goals of the SLF are to: deepen attention to spiritual dimensions of mission and leadership decisions, provide a forum for shared discernment regarding critical strategic leadership challenges, provide personal support to leaders, and build a trusting community of colleagues. The conceptual design of the program consists of tenmodules (of three to four hours duration) scheduled every four to six weeks over a 12 to 18 month period. The process of monthly peer group meetings is a familiar design, pioneered by The Executive Committee, now known as Vistage, and adopted by others (i.e. The Young Presidents Organization). However, the SLF explicitly addresses the spiritual dimension of leadership by integrating theological reflections with social science and managerial readings. Typically the protocol works best with two facilitators, allowing one to attend to the participants and the second to maintain a meta-view of the overall process.

The key structures of each monthly SLF meeting are discussed in turn. Where appropriate, comments from participants in the Oregon SLF pilot, gathered at the conclusion of the program, are used to further illuminate the description of each element 
of the SLF. Specifically, the program structures include: assigning theological, social science, and managerial texts as pre-reading; theme-focused contemplative practices (i.e. meditations and/or reflections) from different religious traditions; a check-in of participant's spiritual and professional status; discussion of pre-readings; charting of individual leadership challenges and shared, non-prescriptive discernment; and the practice of holding others in compassionate, prayerful support. Indicative timing for two possible schedules of the SLF are outlined in Table 1.

\section{Insert Table 1 about here}

\section{Pre-reading}

In advance of each meeting SLF participants receive a selection of readings sourced from a variety of wisdom traditions, social science, and/or managerial texts. Each package is curated to emphasize a particular theme such as:

- The nature of calling/vocation at the senior organizational level.

- Unfolding a personal spirituality appropriate for senior level leadership.

- Spiritual practices to support the complexity of senior leadership agendas.

- Understanding discernment models as a wisdom-overlay on strategic decision-making in the context of senior leadership.

- The responsibilities of senior leaders to advance a justice perspective critical for contemporary healthcare. 
- Deepening the understanding of the strategic vision for the organization in a time of transition.

- Developing wise mentors on behalf of the next generation of leaders.

The topic of each session is explored through readings from a variety of religious and wisdom traditions as well as contemporary leadership and management science. The number and length of readings has evolved in keeping with the adage that less is more. Typically, the readings package consists of three to five short articles or book chapters. A thematic overview on the readings is provided and participants are asked to come prepared to share their perceptions.

\section{Contemplative practices}

Each SLF session begins by reading three short excerpts, from different wisdom traditions, interspersed with contemplative practice. Each passage is carefully selected as appropriate to the topic of the session. One always represents the tradition of the majority of the participants (e.g., in the Oregon pilot this was Christianity). The other two, which speak to the same theme, are taken from different traditions (i.e., Jewish, Muslim, Buddhist, Taoist, Hindu, or secular). This is an important structure for creating the container of religious plurality, as noted by participants in the Oregon SLF pilot:

I find it very helpful to see how different traditions approach a common topic.

These take us to the depth of our own traditions and help us to learn how spiritual matters are expressed in other traditions.

11 
A very specific process is employed with each contemplative reading from the wisdom traditions. Two members, one after the other, read each passage slowly. Then a period of silence and contemplation is held before reading the next text. Beginning with contemplative practice is purposeful. The intention is to ground the leadership challenges discussed within the context of spiritual and wisdom traditions. This is described by Dom Armand Veilleux (2006 n.p.):

Beyond social relations, beyond scientific, philosophical and theological systems, and even beyond religious structures and rituals there is another level of human consciousness, that of religious experience where the true followers of all the religious traditions of humanity recognize one another with a facility that is in proportion to the depth and authenticity of their experience.

This contemplative practice also provides transition from the world of immediate action into the reflective space of the SLF. The ritual helps participants to release the pressures, concerns, and energies of their prior commitments. They have an opportunity to enter a different zone of energy, to quiet, and to become centered in preparation for a deeper level of dialog.

Members of the SLF are religiously diverse, representing the demography of traditions, and non-traditions, within the health care system and broader society. It is important that each step of the process within the SLF respectfully honors religious plurality (Hicks 2003). The religious pluralism encompassed by the opening readings is seen as having two payoffs. It creates a sense of welcome for those outside the dominant tradition represented in the group. It also increases comfort in speaking of spiritual things, 
in a work setting, in an inclusive manner. As noted by participants in the Oregon SLF pilot:

I identify with the Buddhist and Jewish readings more than the Catholic readings. I always find some I like.

Now I am able to connect leadership themes to spiritual themes and have a sense of how to seek out readings when I want to share a spiritual perspective around management challenges in the presence of religious diversity.

The SLF also incorporates a single contemplative reading before the refreshment break and closes the session with a set of three passages. Typically, during the closing, members read a paragraph, or sentence, in a round-robin fashion with silence held between each speaker.

\section{Member check-in}

The member check-in encourages the practice of spiritual self-awareness and builds intimacy among participants. As members enter the room, they fill out the member check-in grid on a whiteboard (Figure 2). Participants place a number from zero to 10 to signal their response to two sentence stems: "Spiritually I am..." and "Professionally I am..." The number represents the state of consolation or desolation (to use spirituality terminology from Ignatius of Loyola) (Aschenbrenner 2004) the member is experiencing. During this segment of the SLF each individual is invited to share a few sentences about the numbers they chose. This activity requires self-awareness and self-disclosure, both of which are integral to forming a culture of authenticity and creating trust. 


\section{Insert Figure 2 about here}

However, learning to self-disclose and embrace the vulnerability implicit in this process is a challenge. For many participants this is a new experience in self-awareness, let alone self-disclosure. They are not used to speaking of their inner life in the workplace.

You have to learn how to do this. You need to learn how to step back and reflect on "where am I"?

You need to shift attention from the outside to the inside.

Yet the process of giving voice to inner musings is an important element in building the capacity for discernment, as described by MacIntosh $(2004,83)$ :

The first step in forming a discerning mind is becoming aware of the pre-conceptions and urgencies that conduct the mind toward an all-too-tidy consistence marked more by its narrowness than its wisdom. ... If the mind is uncultured and narrow in its interests and if it is easily moved by impulses of which it is unaware, then the bias with which it interprets reality will be quite imperceptible to it.

Even in the earliest gatherings this first step is seen as a valued part of the meeting. The process is important for creating sensitivity to the personal and professional challenges of colleagues.

Hearing colleagues self-assessments reflected through the fullness of their humanity creates a very different connection and helps us face challenges together.

It increases the quality of our relationships as a team to discover what is similar and what is different in our experiences. 
More experienced members of the group come to the meeting having already reflected on their inner dispositions. They view this as part of the self-discipline and preparation for the SLF experience, as noted by participants in the Oregon SLF pilot:

I think about how I will check in before I arrive. This is part of my centering of my whole self in order to be able to sense where I am challenged.

Thinking about the check-in before the meeting often leads to insights. This often provokes a topic I want to propose as a Personal Challenge in the second part of the meeting.

The check-in process invites participants to pay attention to and reflect upon their interiority. Several members voiced concern regarding a tendency for some participants to use a family situation in regard to their interior evaluation. While both family and professional circumstances may impact on this assessment, the self-report should focus on this inner state and not simply be a reflection of the "outer" aspects of life. The capacity to become aware of, name and give voice to the interior dimension develops with practice and through observing others. As the SLF experience continues the group develops a sense of psychological safety and participant statements regarding these numbers will become more profound. Through the check-in, the group begins to understand the rhythms of the inner journey as a leader. They become sensitized to the need to integrate mind, heart, spirit and awareness including how a higher power, and/or ultimate values, are present in the action of one's life begins to grow. Thus, the check-in becomes an individualized Examen, shared with the group, that both (in)forms the individual and teaches the group about desolation and consolation. 


\section{Discussion of pre-readings}

The readings are a useful launching pad for dialog. To initiate discussion, the facilitator offers a short reflection disclosing their own personal reactions to one or more of the pre-readings. This step is sufficient to seed the discussion and often no additional prodding is required to fill the allocated sixty-minutes with rich discourse. Participants are invited to comment on the texts and why they are drawn to a particular reading with an emphasis on first person perspectives: What struck ME as helpful, challenging, confusing, inspiring, disturbing... etc. Participants are also encouraged to build off one another's contributions: As I listened carefully while you were speaking, what I learned and/or found inspiring, was provoked by.... However, the intention is not to build consensus or to resolve different perspectives. Instead the diverse points of view and the richness of differentiated understandings are simply appreciated. Participants often find their perceptions evolve based on the insights of others, particularly regarding readings they initially give less credence to. As noted by participants in the Oregon SLF pilot:

Everyone can find their own treasures, then we learn when we share from our diverse points of view.

When I listen to the group, I realize someone always finds something I missed. It is wonderful to learn from others.

Elements of the readings often become iconic in capturing important heuristics surrounding the session's theme; they provide a shared frame of reference among members of the team concerning important leadership topics. Supported by the check-in, 
members quickly learn to bring the readings to bear on the every-day experiences of their professional life. For example, they may reflect on how to think of their work in a new way, incorporate the lesson theme into leadership actions, or use some element to deepen their discernment around a serious decision:

It is great that the readings connect in real time to the challenges we are dealing with.

Having a topic we explore together leads to a common understanding among the team.

The facilitator coordinating the first portion of the meeting serves as a timekeeper, assures that all voices are heard, and brings the discussion to a close. If participants comment on the tyranny of time related to stopping the discussion at 60 minutes, it is important to remember that the process of individual discernment can and will continue after the discussion ends:

It seems like we leave insights on the table, unspoken and not fully processed.

I wish we could drive more fully to the complete implications of the readings.

There is usually no need for a formal summary although the facilitator may choose to reemphasize certain nuances of the learning surrounding the session's readings. Before breaking for refreshments, this portion of the session concludes with thematic contemplative practice, as described in the Contemplative Practices section. Thus, the first half of the meeting is book-ended with opening and closing contemplative practice. 


\section{Refreshment break and charting individual challenges}

Managing the energy of participants is particularly important in the SLF given the intensity of the material covered. A restorative break, scheduled between discussion of the readings and the practice of discernment and compassion, also facilitates the important process of community building. A simple meal is offered that is ideally humble but hearty (e.g., soup, bread and fruit). Alternatively a continental breakfast can be provided if meeting in the morning.

During this period, members of the SLF take time to chart individual challenges. An example of the individual challenges chart is provided (Figure 3). The actual chart used in the session will have sufficient space for each member's notes.

\section{Insert Figure 3 about here}

Individual challenges are issues with which a person is currently wrestling. The challenges can be personal or professional. Each SLF participant names their challenge in a few words on the chart and indicates whether it is an A, B or C challenge. An " $\mathrm{A}$ " challenge is an important issue for discernment that often is time sensitive. For example, assistance in discernment might need to take place within this gathering because there is a critical departmental meeting in two weeks. The promise is that all " $\mathrm{A}$ " challenges will be discussed during the meeting. The member also indicates the approximate amount of time needed to disclose and discuss the challenge; typically " $\mathrm{A}$ " challenges require 15 to 20 


\section{Exploring individual challenges: Practicing discernment and compassion}

minutes. "B" challenges are important issues for discernment but not as urgent or subject to serious time concerns; they are usually accompanied by a request for a 10 to 15 minute slot. "C" challenges are typically early and emergent reflections that can wait until a later meeting if necessary.

This component of the SLF is significant in creating a container for practicing discernment. At this point in the meeting the first facilitator hands over to the second facilitator (roles rotate from meeting to meeting). The facilitator briefly reviews the individual challenges chart to identify the most pressing issues (i.e. " $A$ " challenges) that are dealt with first. To begin, the focal leader describes their challenge. Members of the group are then invited to ask clarifying questions that might help the focal leader think more deeply about the issue, to share experiences that might be informative, or to briefly share knowledge that might be helpful, whether from professional, scientific or spiritual sources. Participants are coached to avoid being prescriptive as the intent is not to identify a solution. Rather, the purpose is to provide a rich set of perspectives from the group to facilitate the focal leader further engaging with the challenge. It is up to the individual wrestling with the challenge to sift through the inputs in order to identify which are helpful versus those that are not. There is no expectation that the focal leader will reach resolution during the meeting. Rather, the intention is to reinforce the value of engaging with the issue in collective, contemplative space. Engaging with the issue may continue 
over an enduring period of time. Many decisions unfold over weeks and months and support is provided during this time as well as during the hard work that often follows a resulting courageous choice. The sharing of real challenges reinforces the practice of selfdisclosure and vulnerability, as noted by participants in the Oregon SLF pilot:

It is important not to see this as the moment to make a change, but rather to evolve a different perspective.

It provides an exercise in courage, to bring problems forth.

SLF has reinforced my ability to confront problems, and to receive and reflect on challenges without having to immediately fix problems. We are learning how the group can be a key source of support.

The facilitator monitors time, makes sure all voices are heard, and with the group seeks to adhere to the time slot appropriate to deal with " $\mathrm{A}$ " and " $\mathrm{B}$ " issues. In a typical four-hour session there is time for $80 \%$ of the members to share a personal challenge. In some sessions, time allows every member to access the group's counsel. The group quickly learns that brevity is a form of compassion; humility is reinforced by not expecting long responses or discourses associated with any one individual's input. However, in moments of serious crisis, empathy tends to override time limitations. When the exchange of insights for a particular issue is complete, the facilitator signals the group to enter into silence by ringing a chime. The facilitator then leads a prayer for the focal leader, as well as all those who will be impacted by this leader's decision, and all leaders wrestling with similar discernments. For example, in the Oregon 
SLF pilot, one challenge a participant shared was whether or not to accept an invitation to move to corporate headquarters. In this case, the language of the prayer was as follows:

Let's hold in our hearts, asking that she come to a wise resolution regarding whether or not she should accept this appointment. Let's also hold in our hearts all the leaders and associates who will be impacted by this program and for whom effective leadership is important, whether or not at this time it should be provided by . Let's also hold in our hearts all our colleagues who struggle to make wise discernments regarding administrative appointments with all the attendant impacts on personal and professional agendas and the well being of our organizational system.

At the conclusion of the prayer the facilitator rings a chime to start another minute of silence. Another chime signals the end of the minute of silence and the facilitator invites a new member of SLF to discuss their challenge. In this manner, individual discernment is practiced in community. Again, the power of ritual is noted by participants in the Oregon SLF pilot:

The power of pausing and entering into silence after the check-in is good.

It helps conclude a very inclusive process.

The process models that all we do ripples beyond the self. At the same time, compassionate concern for the individual wrestling with the challenge is opened to spiritual energy. There is also accountability as the group will inquire about and follow the consequences of earlier decisions. As the program progresses, reference is frequently made to insights from earlier readings and discussions. Individuals who share important challenges feel personally supported and resourced with new insights and perspectives:

I find it helpful and often the dialog and feedback leads to different insights.

We get a perspective that is different from those in other meetings. 


\section{Discussion}

The operationalization of spiritual leadership development through the SLF protocol provides a foundation that can inform future practice and research: operationalizing the intersection of leadership, spirituality and learning; illustrating the role of shared contemplative practice; outlining the importance of structure in holding space for spiritual plurality.

The SLF protocol is explicit in establishing the connection between leadership, spirituality and learning. Leadership is framed as an ongoing, interior journey that is intimately related to one's individual spirituality; the journey is the destination (Vail, 1996). Spirituality and the process of ongoing discernment infuses both the learning goals and content themes of the program. Each design element invites participants to explore layers of spirituality, including their relationship with self, others, the world and their higher-power. The readings and reflections function as projective techniques to build awareness of their ontological assumptions: who they believe themselves to be, how they are similar and different to others, and the values they use to guide their actions in the world. The individual challenges element of the SLF protocol requires participants to practice transcendental awareness, as described by Barney et al. $(2015,301)$ :

Transcendental awareness requires self-questioning in order to see a world that one mutually co-constructs and participants in. This awareness involves practices that enhance the questioning of existing beliefs, assumptions and values, and acceptance of the responsibility each of us has in creating this world. 
SLF is an exemplar of developing Fry and Krieger's (2009) being-centered leadership where, at increasing levels of complexity, boundaries between self and other become more permeable and the capacity for non-duality increases. Participants in the pilot SLF perceived an increase in their use of collaborative behaviors (i.e. more skillful listening, greater patience, and less micro-management) and mission/vision-driven styles of leadership, which they attributed to the SLF experience. While the SLF pilot did not explicitly explore the relationships with stakeholders beyond the organization, such as the environment, it would be a natural inclusion to the program given the "rising sustainability consciousness is built on higher-level value systems that support the sacredness of people and nature" (Stead and Stead 2014, 143). An interesting line of inquiry for future research would be to track the developmental trajectories of these layers of relationship (i.e. at the individual, group and possibly organizational levels) during and after participation in a protocol like the SLF.

Each design element of the SLF protocol employs at least one of the contemplative practices detailed by Pavlovich (2010): reflection, mindfulness, and presencing. Further, the SLF design illustrates individual contemplative practice in a group context: group readings from a variety of wisdom traditions followed by periods of silence and contemplation; individual reflection and disclosure of spiritual equilibrium, or lack thereof, during the member check-in; sharing first-person perspectives on the assigned readings; and practicing discernment and compassion during the individual 
challenges. Complex phenomena, such as leadership and emotional intelligence, operate at the individual and group level (Day 2001; Druskat and Wolff 2001). Similarly, the capacity for discernment is relevant at the individual, group and whole system level, as demonstrated by Delbecq et al. $(2004,148)$ :

Who am I? Where am I going? What am I to do? How do I make sense of life, of my life? What will I leave behind as my inheritance to the next generation? These are all discernment questions. Institutions, too, must answer to a version of these identity questions: Why is this institution in existence? For what purpose was it founded (shall I/we found it?) Does it still serve that purpose?

Consequently, another interesting line of future inquiry concerns how opportunities for shared contemplative practice might be incorporated into other organizational spaces and practices. Equally of interest, what effect does group level practice have on individual practice, behavioral norms and organizational outcomes?

Finally, the detailed description of the SLF design contributes to understanding how structure can support the integration of spirituality in leadership development: clarity of learning objectives; utilizing a cohort model to facilitate group development; attention to (non)religious plurality; establishing the norm of first-person commentary; an appropriate number of facilitators; and the use of rituals to support the learning. For example, SLF rituals include the member check-in, the use of silence, a chime used to signal the beginning and ending of silence, the shared meal and finally, consistent format and timings for each meeting. We note that historically the pilot SLF was once shortened to three hours. However, it became evident that a full four hours is needed. 


\section{Conclusion}

In this paper, we explored a protocol used to incorporate spiritual wisdom in leadership development: the Spiritual Leadership Forum (SLF). The primary objective of the SLF is to engage participating members in a shared developmental dialog that employs contemplative practices, disclosure of personal and professional conditions, discussion of theme based pre-assigned readings, sharing of individual challenges and the practice of discernment. The specific design of the SLF learning experience offers an exemplar for future practice. The diverse contemplative reflections are an important characteristic in light of the increasing spiritual and cultural diversity among leaders. The check-in process provides an interpersonal context for team members to exchange information about themselves that creates and strengthens cohesion. The set of spiritual and secular readings provide a springboard for dialog that can take off in productive directions. Finally, the element of being held in heart and silence is an impactful and unique experience for participants, particularly in contrast to the rest of corporate life. Anecdotally, participants reported individual, team and organizational level benefits that flow from the SLF experience. The particular SLF design implies that spiritual leadership development protocols should address the multiple layers of relationship, incorporate shared contemplative practice, and provide appropriate types of structure. However, further research is required to validate these assertions. 
Including this article in the special issue honoring André fittingly provides a logical book end to his early explorations of spirituality and leadership development (Delbecq, 2000), and achieves his intention of sharing the protocol more broadly. Hopefully the SLF can serve as a template for others to experiment with and expand upon, furthering the legacy of André Delbecq as a pioneer in this area of practice and scholarship.

\section{REFERENCES}

Antonacopoulou, E. P., and R. F. Bento. 2004. “Methods of 'Learning Leadership': Taught and Experiential." In Leadership In Organizations, edited by John Storey, 81-103. New York: Routledge. New York, NY P. 81-103

Aschenbrenner, G.A. 2004. Stretched for Greater Glory: What to Expect From the Spiritual Exercises. Chicago: Loyola Press.

Barney, J.B., J. Wicks, O.C. Scharmer, and K. Pavlovich. 2015. "Exploring Transcendental Leadership: A Conversation." Journal of Management, Spirituality and Religion 12 (4): 290-304.

Bento, R.F. 2000. "The Little Inn at the Crossroads: A Spiritual Approach to the Design of a Leadership Course." Journal of Management Education 24 (5): 650-661.

Biberman, J., M. Whitty, S. King, and J.A. Neal. 1999. "Innovative Management Training: Combining the Wisdom of East and West." Chinmaya Management Review 3 (1): 5-13.

Bolman, L.G. and T.E. Deal. 2001. Leading with Soul. San Francisco: John Wiley and Sons.

Carter, T.J. 2002. “The Importance of Talk to Midcareer Women's Development: A Collaborative Inquiry." Journal of Business Communication 39 (1): 55-91.

Cavanagh, G.F. 1999. "Spirituality for Managers: Context and Critique." Journal of Organizational Change Management 12 (3): 186-199. 
Charles, G.L., F. Travis, and J. Smith. 2014. "Policing and Spirituality: Their Impact on Brain Integration and Consciousness." Journal of Management, Spirituality and Religion 11 (3): 230-244.

CMind. n.d. "The Tree of Contemplative Practices." Retrieved 10 June 2019 from: http://www.contemplativemind.org/practices/tree

Cowan, D.A. 2005. "Translating Spiritual Intelligence into Leadership Competencies.” Journal of Management, Spirituality and Religion 2 (1): 3-38.

Day, D.V. 2001. "Leadership Development: A Review In Context.” The Leadership Quarterly 11 (4): 581-613.

Deal, T.E., and A. A. Kennedy. 2000. Corporate Cultures: The Rites and Rituals of Corporate Life. Cambridge, MA: Perseus Books Publishing.

Delbecq, A.L. 2000. "Spirituality for Business Leadership: Reporting on a Pilot Course for MBAs and CEOs." Journal of Management Inquiry 9 (2): 117-128.

Delbecq, A.L., E. Liebert, J. Mostyn, P.C. Nutt, and G. Walter. 2004. "Discernment and Strategic Decision Making: Reflections for a Spirituality of Organizational Leadership." In Spiritual Intelligence at Work: Meaning, Metaphor, and Morals, Vol. 5, edited by M. Pava and P. Primeaux, 139-174. United Kingdom: Emerald Publishing Limited.

Druskat, V. U. and S. B. Wolff. 2001. "Building the Emotional Intelligence of Groups." Harvard Business Review 79 (3): 80-91.

Eisen, M.J. 2001. "Peer-Based Professional Development Viewed Through the Lens of Transformative Learning." Holistic Nursing Practice 16 (1): 30-42.

Fry, L.W. and M. Kriger. 2009. "Towards a Theory of Being-Centered Leadership: Multiple Levels of Being as Context for Effective Leadership." Human Relations 62 (11): 1667-1696.

Fry, L.W. and M. Nisiewicz. 2013. Maximizing the Triple Bottom Line Through Spiritual Leadership. Stanford: Stanford University Press.

Hicks, D. A. 2003. Religion and the Workplace: Pluralism, Spirituality, Leadership. Cambridge, MA: Cambridge University Press.

Howard, S. 2002. "A Spiritual Perspective on Learning in the Workplace." Journal of Managerial Psychology 17 (3): 230-242. 
Kabat-Zinn, J. 2003. Mindfulness-Based Interventions in Context: Past, Present, and Future. Clinical Psychology: Science and Practice 10 (2): 144-156.

Kernochan, R.A., D. W. Mccormick, and J.A. White. 2007. "Spirituality and the Management Teacher: Reflections of Three Buddhists on Compassion, Mindfulness, and Selflessness in the Classroom." Journal of Management Inquiry 16 (1): 61-75.

Korac-Kakabadse, N., A. Kouzmin, and A. Kakabadse. 2002. "Spirituality and Leadership Praxis.” Journal of Managerial Psychology 17 (3): 165-182.

Kouzes, J. M., and B. Z. Posner. 2006. The Leadership Challenge (Vol. 3). Hoboken, NJ: John Wiley and Sons.

Lips-Wiersma, M. 2004. "Furthering Management and Spirituality Education Through the Use of Paradox." Journal of Management Education 28 (1): 119-133.

Macintosh, M.A. 2004. Discernment and Truth: The Spirituality and Theology of Knowledge. New York: Crossroad Publishing Company.

Mackey, J., and R. Sisodia. 2014. Conscious Capitalism: Liberating the Heroic Spirit of Business. Boston: Harvard Business Review Press.

Marcic, D. 2000. “God, Faith, and Management Education.” Journal of Management Education 24 (5): 628-649.

McClintock, A.S., M.A. Rodriguez, and N. Zerubavel. 2019. "The Effects of Mindfulness Retreats on the Psychological Health of Non-Clinical Adults: A Meta-Analysis." Mindfulness 10 (8): 1443-1454.

Mezirow, J. 1996. “Contemporary Paradigms of Learning.” Adult Education Quarterly 46 (3): 158-172.

Palmer, P. J. 1999. Let Your Life Speak: Listening for the Voice of Vocation. San Francisco: Jossey-Bass.

Pavlovich, K. 2010. "Educating for Conscious Awareness." Journal of Management, Spirituality and Religion 7 (3): 193-208.

Reibel, D.K., J.M. Greeson, G.C. Brainard, and S. Rosenzweig. 2001. "MindfulnessBased Stress Reduction and Health-Related Quality of Life in a Heterogeneous Patient Population." General Hospital Psychiatry, 23 (4):183-92. 
Sable, D. 2014. "Reason in the Service of the Heart: The Impacts of Contemplative Practices on Critical Thinking." The Journal of Contemplative Inquiry 1 (1): 1-22.

Scharmer, C. O. and K. Kaufer. 2013. Leading From the Emerging Future: From EgoSystem to Eco-System Economies. San-Francisco: Berrett-Koehler Publishers.

Schmidt-Wilk, J., C.N. Alexander, and G.C. Swanson. 1996. "Developing Consciousness in Organizations: The Transcendental Meditation Program in Business." Journal of Business and Psychology 10 (4): 429-444.

Schmidt-Wilk, J. 2000. "Consciousness-Based Management Development: Case Studies of International Top Management Teams." Journal of Transnational Management Development 5 (3): 61-85.

Schmidt-Wilk, J., D.P. Heaton, and D. Steingard. 2000. "Higher Education for Higher Consciousness: Maharishi University of Management as a Model for Spirituality in Management Education.” Journal of Management Education 24 (5): 580-611.

Sivilli, T.and T. Pace. 2014. The Human Dimensions of Resilience: A Theory of Contemplative Practices and Resilience. The Garrison Institute. Retrieved 1 June 2019 from:

http://www.garrisoninstitute.org/downloads/cbrt/The Human Dimensions of Resilience. $\underline{\mathrm{pdf}}$

Slemp, G.R., H.K. Jach, A. Chia, D.J. Loton, and M.L. Kern. 2019. "Contemplative Interventions and Employee Distress: A Meta-Analysis." Stress and Health 35 (3): 227 255.

Stead, J.G. and W.E. Stead. 2014. "Building Spiritual Capabilities to Sustain Sustainability-Based Competitive Advantages." Journal of Management, Spirituality and Religion 11 (2): 143-158.

Tackeny, C., S.F. Chappell,

Tisdell, E. and D.E. Tolliver. 2001. "The Role of Spirituality in Culturally Relevant and Transformative Adult Education." Adult Learning 12 (3): 13-14.

Vail, P. 1996. Learning as a Way of Being: Strategies for Survival In a World of Permanent White Water, San Francisco: Jossey-Bass.

Veilleux, A., 2006. "Beyond Reason: Monastic Interreligious Dialogue and Islam." Translated by William Skudlarek, OSB. Translation Retrieved From Http://Www.Scourmont.Be/Armand/Writings/Raison-En.Htm 
Waddock, S. and J.M. Lozano. 2013. "Developing More Holistic Management Education: Lessons Learned From Two Programs." Academy of Management Learning and Education 12 (2): 265-284.

Wahid, N.K.A. and N.M. Mustamil. 2014. "Communities of Practice, Workplace Spirituality, and Knowledge Sharing." International Business and Management 9 (1): 3543.

Ziegler, M.F., T.M. Paulus, and M. Woodside. 2006. "This Course is Helping Us All Arrive at New Viewpoints, Isn't It? Making Meaning Through Dialogue in a Blended Environment." Journal of Transformative Education 4 (4): 302-319. 
Figure 1:

\section{The Tree of Contemplative Practices (CMind n.d.)}

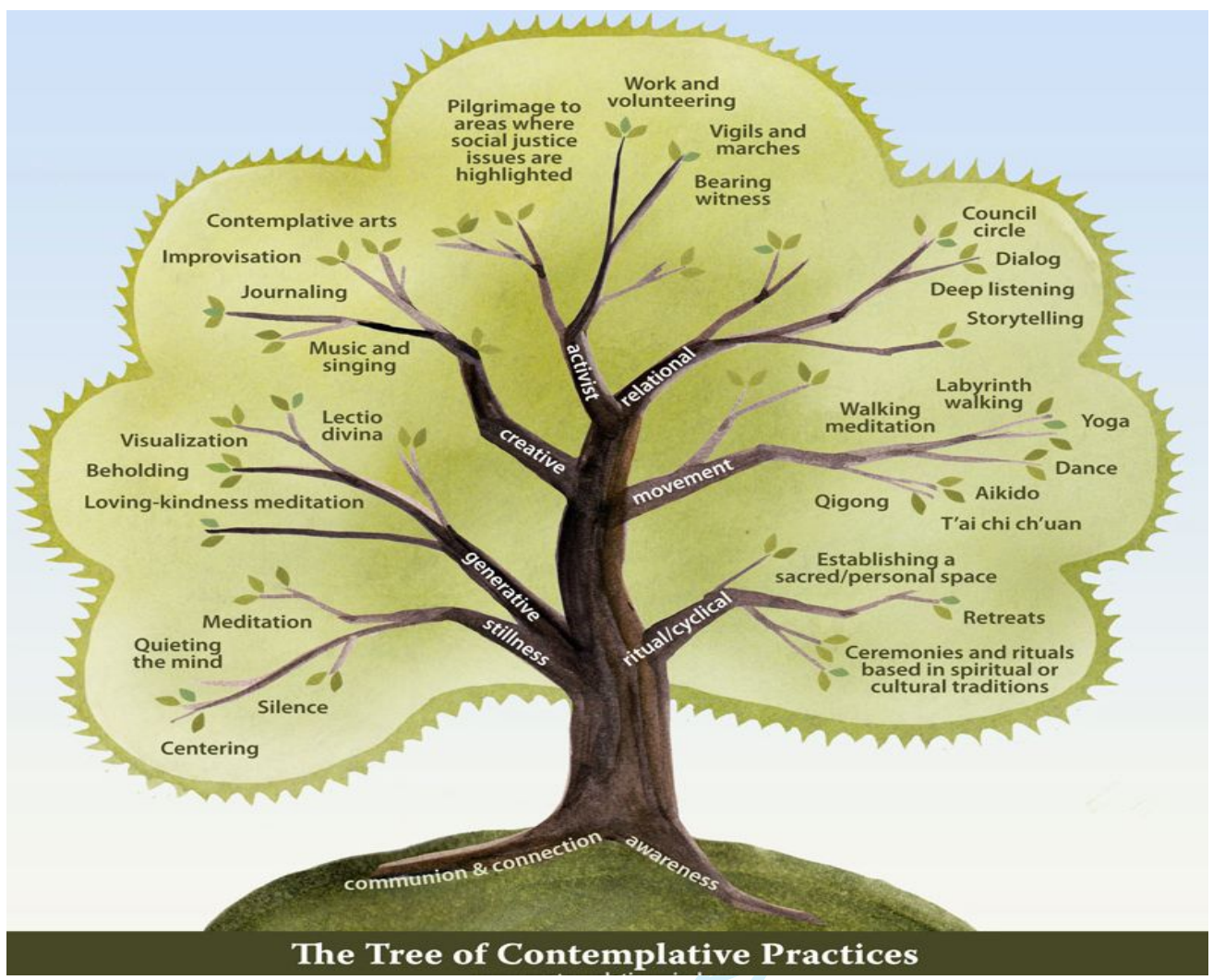




\section{Table 1:}

Sample Schedules

\begin{tabular}{|c|c|c|}
\hline \multicolumn{2}{|c|}{ Indicative Timings } & \multirow[b]{2}{*}{ Session Element } \\
\hline 3 hr Session & $4 \mathrm{hr}$ Session & \\
\hline $\begin{array}{c}0-10 \mathrm{~min} \\
(10 \mathrm{~min} \text { total })\end{array}$ & $\begin{array}{c}0-10 \mathrm{~min} \\
(10 \mathrm{~min} \text { total })\end{array}$ & Opening Meditation \\
\hline $\begin{array}{c}10-30 \mathrm{~min} \\
(20 \mathrm{~min} \text { total })\end{array}$ & $\begin{array}{c}10-30 \mathrm{~min} \\
(20 \mathrm{~min} \text { total })\end{array}$ & Member Check-In \\
\hline $\begin{array}{l}30-90 \text { min } \\
(60 \text { min total })\end{array}$ & $\begin{array}{c}30-90 \mathrm{~min} \\
(60 \mathrm{~min} \text { total })\end{array}$ & Discussion of Readings \\
\hline $\begin{array}{l}90-110 \mathrm{~min} \\
(20 \mathrm{~min} \text { total })\end{array}$ & $\begin{array}{l}90-120 \mathrm{~min} \\
(30 \mathrm{~min} \text { total })\end{array}$ & $\begin{array}{c}\text { Light Supper / Stretch Break } \\
+ \\
\text { Fill-in Current Topics Chart }\end{array}$ \\
\hline $\begin{array}{l}110-170 \mathrm{~min} \\
(60 \mathrm{~min} \text { total })\end{array}$ & $\begin{array}{l}120-235 \text { min } \\
(115 \text { min total })\end{array}$ & $\begin{array}{l}\text { Discussion of Individual } \\
\text { Members Challenges }\end{array}$ \\
\hline $\begin{array}{l}170-180 \mathrm{~min} \\
(10 \mathrm{~min} \text { total })\end{array}$ & $\begin{array}{l}235-240 \mathrm{~min} \\
(5 \mathrm{~min} \text { total })\end{array}$ & $\begin{array}{c}\text { Closing Reflection / } \\
\text { Meditation }\end{array}$ \\
\hline
\end{tabular}


Figure 2:

\section{Member Check-In Table}

\begin{tabular}{|c|c|c|c|}
\hline $\begin{array}{c}\text { Professionally } \\
\text { I'm.... } \\
\{\mathbf{1 - 1 0}\end{array}$ & $\begin{array}{c}\text { Spiritually } \\
\text { I'm... } \\
\{\mathbf{1 - 1 0}\}\end{array}$ & Member & $\begin{array}{c}\text { Professional/ } \\
\text { Spiritual Challenges }\end{array}$ \\
\hline & & & \\
& & & \\
\hline & & & \\
\hline
\end{tabular}


Figure 3:

\section{Individual Challenges/Current Topics}

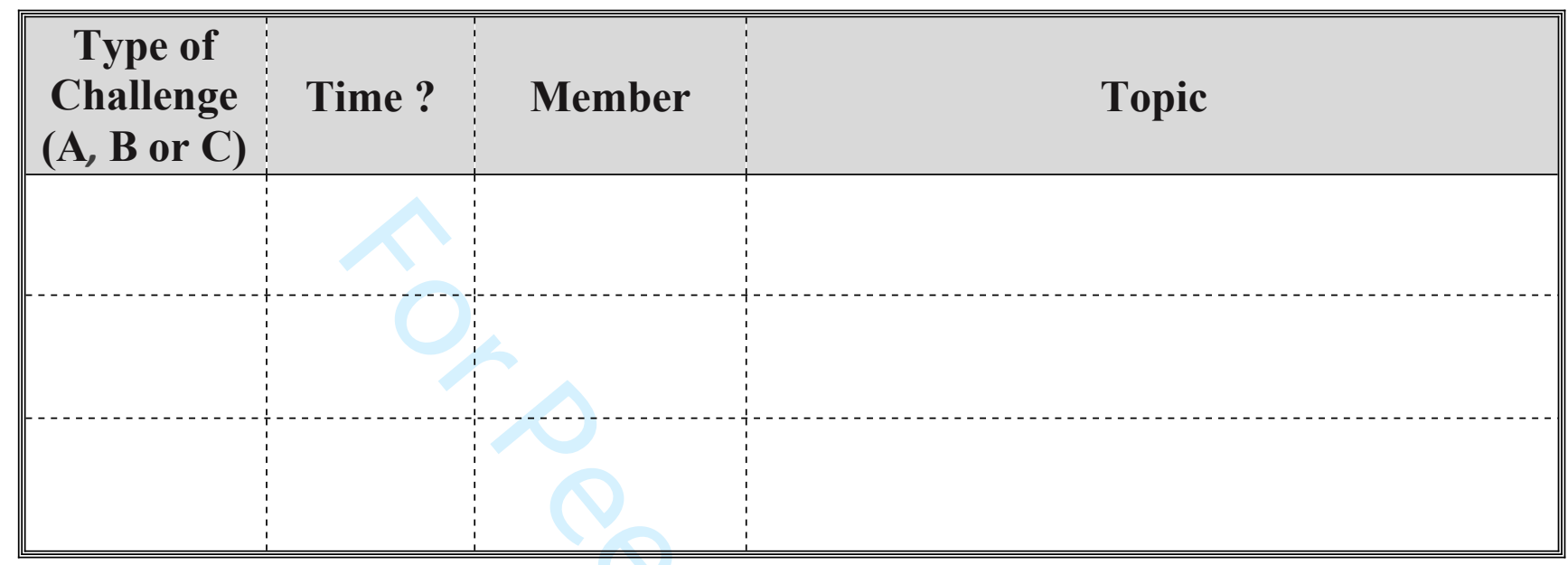

